\title{
Harmonics and Neutral Line Current Compensation in Three-Phase Four-Wire Power Systems
}

\author{
Maxim O. Chernyshov, \\ Valery P. Dovgun, Irina G. Vazhenina, \\ Sergei A. Temerbaev and Victor V. Novikov* \\ Siberian Federal University \\ 79 Svobodny, Krasnoyarsk, 660041, Russia
}

Received 20.09.2017, received in revised form 07.04.2018, accepted 06.05.2018

Load unbalance and modern office equipment result in a significant neutral current in three-phase four-wire low-voltage power systems. This paper considers a new configuration of hybrid power filter for power quality management in three-phase four-wire low voltage power systems. The proposed hybrid filter is composed of a single-phase power converter and a three-phase passive filter connected in series. The hybrid filter can be operated in both passive and hybrid mode.

The compensating performance of the filter is confirmed with computer simulation using MATLAB software. Analysis and simulation proved that the hybrid filter is an effective solution for neutral current mitigation.

Keywords: three-phase four-wire power system, hybrid power filter, neutral line current.

Citation: Chernyshov M.O., Dovgun V.P., Vazhenina I.G., Temerbaev S.A., Novikov V.V. Harmonics and neutral line current compensation in three-phase four-wire power systems, J. Sib. Fed. Univ. Eng. technol., 2018, 11(5), 550-559. DOI $10.17516 / 1999-494 X-0053$

\section{Компенсация высших гармоник \\ и токов нейтральных проводников \\ в трехфазных четырехпроводных сетях}

М.О. Чернышов, В.П. Довгун, И.Г. Важенина, С.А. Темербаев, В.В. Новиков Сибирский федеральный университет Россия, 660041, Красноярск, пр. Свободныий, 79

Современное офисное оборудование и несимметрия нагрузок являются основной причиной увеличения токов нейтральных проводников в трехфазных четырехпроводных сетях низкого

(C) Siberian Federal University. All rights reserved

* Corresponding author E-mail address: chernyshov.m.o@gmail.com, irina-vazhenina@mail.ru 
напряжения. В статье рассмотрена новая конфигурация силового гибридного фильтра для управления качеством электроэнергии в трехфазных четырехпроводных сетях. Предложенный гибридный фильтр образован последовательным соединением трехфазного пассивного фильтра, настроенного на частоту доминирующей третьей гармоники, и однофазного инвертора. Фильтр может работать как в пассивном, так и в гибридном режиме.

Компенсационные характеристики предложенного фильтра проанализированы с помощью моделирования в MATLAB. Анализ показал, что предложенный гибридный фильтр является эффективным средством ослабления гармоник и токов нейтральных проводников.

Ключевые слова: трехфазная четырехпроводная сеть, гибридный силовой фильтр, ток нейтрального провода.

\section{Introduction}

Three-phase four-wire distribution power systems are widely used in office buildings and commercial complexes to supply single-phase and three-phase loads. These loads include office equipment, computer systems, fluorescent and diode lighting systems, adjustable-speed drivers and have nonlinear characteristics. Nonlinear loads create problems of high current harmonics and excessive neutral current since triplen harmonics are summed in the neutral conductor. Under the worst case, the neutral current could be 1.73 times exceed the phase current [1,2]. High level of neutral harmonic current results in transformer and conductor overheating, voltage distortions [3]. Singlephase loads may be distributed unequally, which results in serious load unbalance and excessive neutral-line fundamental current. Therefore excessive neutral currents are becoming a significant problem in modern low voltage power distribution systems.

Different neutral current compensation techniques have been proposed [4-8]. A passive neutral current suppressor in the form of zig-zag transformer connected in parallel to the load was considered in [4]. However, the effectiveness of passive neutral-current suppressors depends on the ratio between the impedance of the distribution system and the passive filter. Furthermore the zig-zag transformer provides a low impedance path for zero-sequence components of the utility voltage.

A hybrid neutral-current suppressor consisting a zig-zag transformer connected in parallel with the load and a single-phase active filter which in its turn is connected in series with the neutral conductor was proposed in [5]. However, a converter inserted at the neutral line may cause fluctuations of the voltage between neutral points of the load and the distribution system [8]. The neutral voltage variations may cause improper operation of the sensitive electronic equipment.

Several neutral current compensation systems in the form of three-phase four-wire active power filter were proposed in $[5,6]$. But this configurations has the disadvantage of complexity of control and a big number of semiconductor switches. The capacity and cost of three-phase four-wire converters are very high as compared with other types of power filters. This limits wide application of active power filters. Hybrid power filters (HPF) may be more attractive solution for neutral current mitigation.

In this paper the new configuration of the hybrid filter for neutral-line current and voltage mitigation in tree-phase four-wire distribution power systems is considered.

\section{System configuration of hybrid power filter}

The configuration of the proposed power filter is shown in Fig. 1. It comprises a three phase passive filter tuned for third harmonic and a single-phase power converter connected in series. Power 


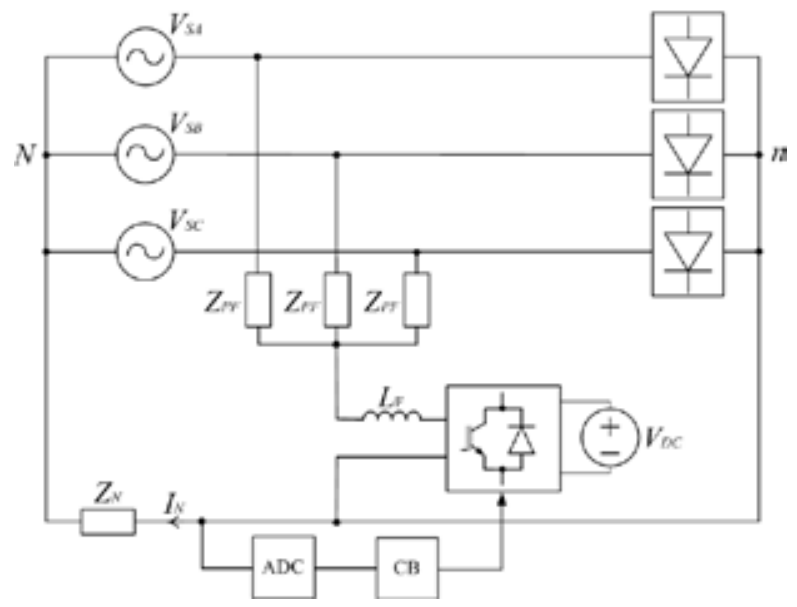

Fig. 1. The system configuration of the hybrid filter for neutral current harmonics mitigation

converter acts as an active filter. The voltage rating of the power converter can be significantly reduced because major part of the phase to neutral voltage drops on the passive filter. The hybrid filter can operate in either passive or hybrid mode. In Fig. 1 ADC - analog to digital converter, CB - control block.

Computation of the output voltage of the power converter is performed by the digital twoband frequency-dividing filter which realizes bandpass and band-stop magnitude characteristics. The output voltage of the active filter is proportional to harmonic components of the neutral-line current $I_{N}$ :

$$
u_{A F}=R_{A F 1} i_{N}^{(1)}+R_{A F h} i_{N}^{(h)}
$$

where $i_{N}^{(1)}$ and $i_{N}^{(h)}$ are fundamental and harmonic components of the neutral current, respectively; $R_{A F 1}$ and $R_{A F h}$ are transfer resistances of the active filter on the fundamental and harmonics frequencies. The output signals of the two-band filter are amplified and sent to the PWM circuit as the modulation signal.

The current flowing through the neutral conductor is only the zero sequence component. The zero-sequence equivalent circuit of the three-phase four-wire distribution power system with the proposed hybrid filter is shown in Fig. 2, where $V_{S}^{0}$ is a zero-sequence voltage source modeling the

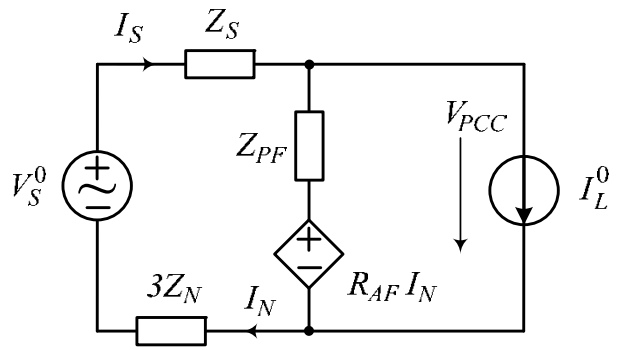

Fig. 2. The zero-sequence equivalent circuit of the distribution power system 
unbalanced utility voltage or nonsymmetrical linear load, $I_{L}^{0}$ is the zero- sequence current source caused by the nonlinear load. $Z_{S}$ and $Z_{N}$ are the phase-line impedance and neutral-line impedance of the distribution system, respectively. $Z_{P F}$ is the impedance of the passive filter. Active power filter is considered as a current controlled voltage source with output voltage according to the formula (1).

According to Fig. 2 the neutral-line current $I_{N}$ can be derived as

$$
I_{N}=\frac{U_{n N}}{Z_{N}}=\frac{3 V_{S}^{0}}{Z_{S}+Z_{P F}+3\left(Z_{N}+R_{A F}\right)}+\frac{3 Z_{P F} I_{L}^{0}}{Z_{S}+Z_{P F}+3\left(Z_{N}+R_{A F}\right)} .
$$

Voltage in the point of common coupling (PCC)

$$
V_{P C C}=\frac{\left(Z_{P F}+3 R_{A F}\right) V_{S}^{0}}{Z_{S}+Z_{P F}+3\left(Z_{N}+R_{A F}\right)}+\frac{Z_{P F}\left(Z_{S}+3 R_{A F}\right) I_{L}^{0}}{Z_{S}+Z_{P F}+3\left(Z_{N}+R_{A F}\right)} .
$$

Equations $(2,3)$ may be applied for the analysis of compensating characteristics of the hybrid filter for zero-sequence components. As seen in $(2,3)$, operation of the active power filter is equivalent to inserting a resistor $R_{A F}$ in series with neutral-line impedance of the distribution system. Hence, harmonics of the neutral-line current and the voltage $V_{P C C}$ can be suppressed more effectively.

\section{Calculation Of The Compensating Signal}

Control strategies to generate compensating signals for active filters are based on the frequencydomain or time-domain techniques $[9,10]$. Control strategy in the frequency domain is based on the Fourier analysis of the distorted current or voltage. The high-order harmonic components are separated from distorted signals and combined to form compensating commands. But the discrete Fourier transform (DFT) loses accuracy in nonstationary situations. Commonly used calculation methods in the time domain are the instantaneous reactive (P-Q) theory approach, neural network theory, notch filter approach, adaptive signal processing. Most of these algorithms have a much better dynamic response than the DFT. In this paper computation of the compensation signal is performed by the two-band infinite impulse response (IIR) filter (Fig. 3). It realizes two double-complementary transfer functions:

$$
\begin{aligned}
& F_{1}(z)=\frac{E_{n}(z)}{X(z)}=\frac{1}{2}[1+A(z)], \\
& F_{2}(z)=\frac{E_{b p}(z)}{X(z)}=\frac{1}{2}[1-A(z)],
\end{aligned}
$$

where $A(z)$ is a second-order all-pass transfer function. $F_{1}(z)$ is a notch-type transfer function and $F_{2}(z)$ is a bandpass-type transfer function tuned to the fundamental frequency $\omega_{0}$.

A ladder-form realization of all-pass IIR digital filter is shown in Fig. 4. In Fig. $4 x(n)$ and $y(n)$ are input and output signals, respectively. Transfer function of the ladder all-pass filter is the following:

$$
\begin{gathered}
A(z)=\frac{Y(z)}{X(z)}=\frac{z^{-2}+k_{1}\left(1+k_{2}\right) z^{-1}+k_{2}}{k_{2} z^{-2}+k_{1}\left(1+k_{2}\right) z^{-1}+1} . \\
-553-
\end{gathered}
$$




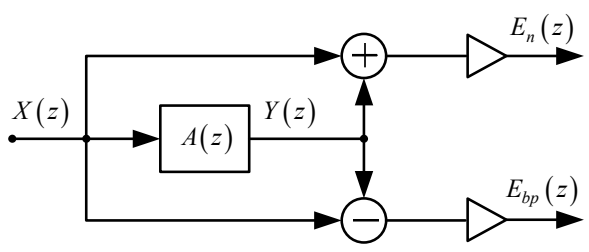

Fig. 3. Two-band IIR filter

The polynomials of nominator and denominator of equation (6) have mirror symmetry. Ladder IIR filter (Fig. 4) realizes all-pass transfer function module of which is equal to 1 in the all frequency range. According to $(4,5)$, transfer functions of the two-band IIR filter, shown in Fig. 3, are the following:

$$
\begin{aligned}
& F_{1}(z)=\frac{1}{2} \frac{\left(z^{-2}+2 k_{1} z^{-1}+1\right)\left(1+k_{2}\right)}{k_{2} z^{-2}+k_{1}\left(1+k_{2}\right) z^{-1}+1}, \\
& F_{2}(z)=\frac{1}{2} \frac{\left(1-k_{2}\right)\left(z^{-2}-1\right)}{k_{2} z^{-2}+k_{1}\left(1+k_{2}\right) z^{-1}+1}
\end{aligned}
$$

where $k_{1}$ is the adaptive coefficient, which should converge to $-\cos \omega_{0}$ for reject a sinusoid with frequency $\omega_{0}$. Suppression frequency of the notch filter can be modified by $k_{1}$ and stopband width by $k_{2}$.

The all-pass IIR filter in Fig. 4 is adapted using adaptive algorithms related to the lattice finite impulse response (FIR) filters. The lattice structure of second-order FIR filter is shown in Fig. 5 . Adaptation algorithm of the FIR lattice was considered in [11].

\section{MATLAB-based modeling of the proposed filter}

Traditionally, nonlinear loads are represented as current sources. However, single-phase diode rectifiers in most cases have capacitive smoothing filters. This type of nonlinear load is equivalent to a

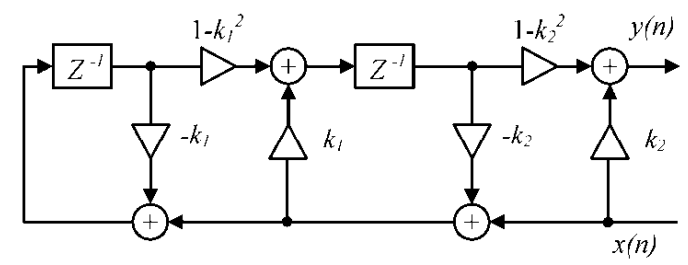

Fig. 4. Ladder structure of second-order all-pass IIR filter

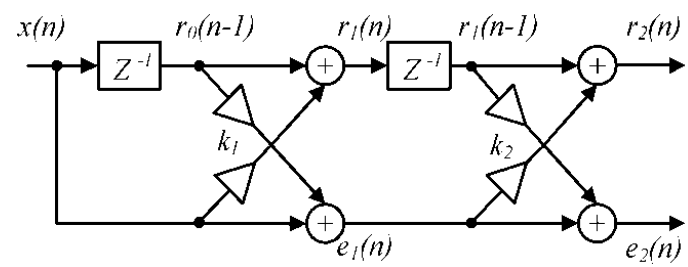

Fig. 5. Second-order FIR lattice filter 
voltage source with small impedance $[2,12]$. Common shunt passive and active filters have been shown in [12] to have different compensation characteristics for current-source nonlinear loads and voltagesource nonlinear loads. In this section we consider compensation characteristics of the proposed filter for different rectifier loads.

Case A: diode rectifier has the RLC load. The MATLAB model of the distribution power system, hybrid filter and the load is shown in Fig. 6. The nonlinear load consists of three single-phase diode rectifiers with a LC smoothing filters. Each rectifier is connected between line and neutral point. The linear load is modeled by the series RL network in each phase. Parameters used in the computer simulation are shown in Table I.

Fig. 7 shows the simulation results for the neutral current in the case of applying the passive filter and the hybrid filter. The passive filter is connected in $0,2 \mathrm{~s}$. The filter works in the passive mode until 0,4s when the power convertor starts. As seen in Fig. 7, the neutral current is attenuated from 30 A to less than 5.3 A (RMS).

The harmonic content of the neutral current is shown in Fig. 8. The total harmonic distortion (THD) of the PCC voltage is less than $4 \%$.

Fig. 9, 10 show the simulation results for the unbalanced RLC load. In this case the neutral current contains both triplen and fundamental harmonics. Active power filter does not influence over neutralline fundamental harmonic.

Table 1. Model parameters used in the simulation (RLC load)

\begin{tabular}{|c|c|}
\hline Parameter & Value \\
\hline $\mathrm{R}_{\mathrm{S}}, \mathrm{L}_{\mathrm{S}}$ & $0,1 \Omega, 318 \mu \mathrm{H}$ \\
\hline $\mathrm{R}_{\mathrm{N}}$ & $0,1 \Omega$ \\
\hline $\mathrm{R}_{\mathrm{L}}, \mathrm{L}_{\mathrm{L}}, \mathrm{C}_{\mathrm{L}}$ & $40 \Omega, 1.2 \mathrm{mH}, 530 \mu \mathrm{F}$ \\
\hline $\mathrm{R}_{\mathrm{LL}}, \mathrm{L}_{\mathrm{LL}}$ & $15 \Omega, 47.7 \mathrm{mH}$ \\
\hline $\mathrm{V}_{\mathrm{S}}$ & $220 \mathrm{~V}, 50 \mathrm{~Hz}$ \\
\hline
\end{tabular}

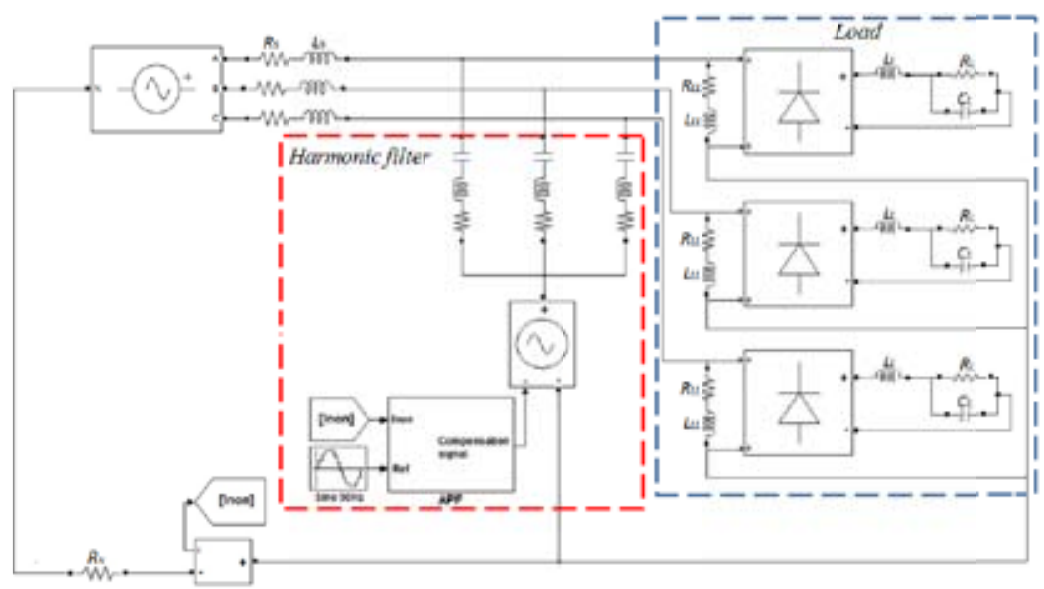

Fig. 6. The MATLAB model of the hybrid filter and the distribution power system (RLC load) 


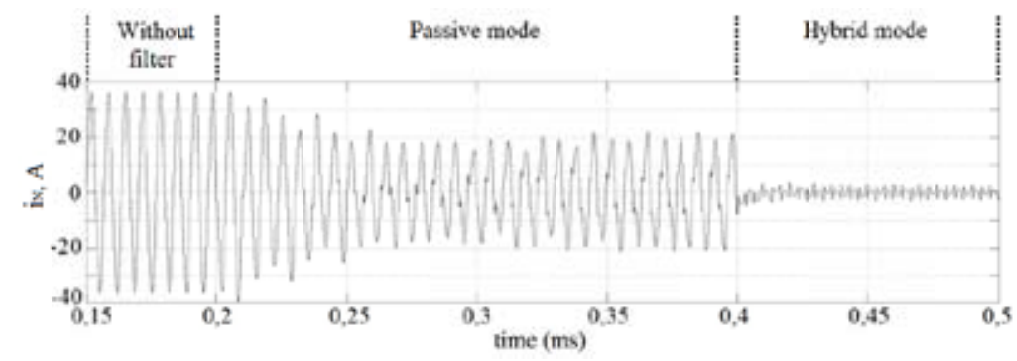

Fig. 7. Waveform of the neutral line current $I_{N}$ (balanced RLC load)

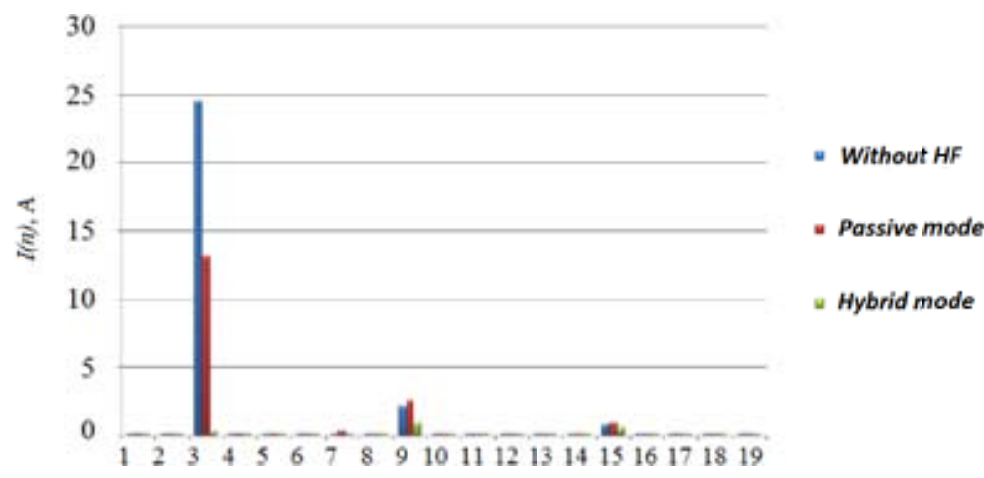

Fig. 8. Spectrum of the neutral line current $I_{N}$ (balanced RLC load)

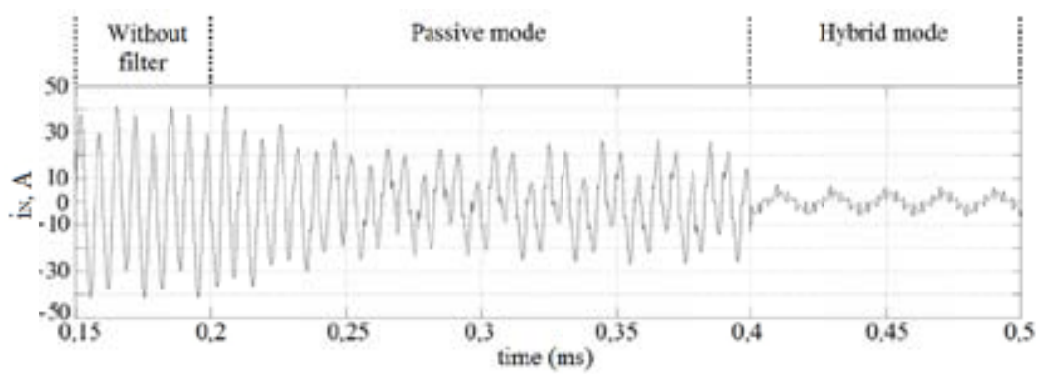

Fig. 9. Waveform of the neutral line current $I_{N}$ (unbalanced RLC load)

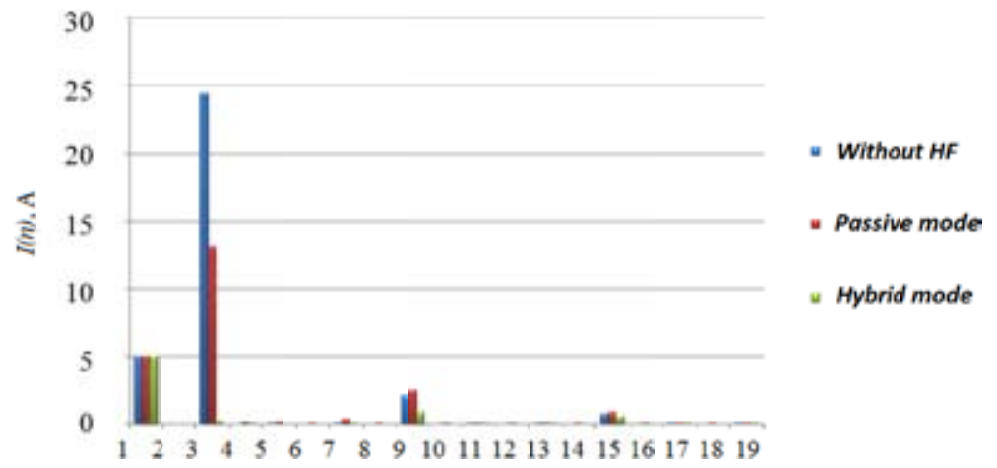

Fig. 10. Spectrum of the neutral line current $I_{N}$ (unbalanced RLC load) 
Case B: diode rectifiers have the RC load. The MATLAB model of the load, hybrid filter and the distribution power system is shown in Fig. 11. The nonlinear load consists of three single-phase diode rectifiers with a load of capacitor and resistor connected in parallel. The parameters used in the computer simulation are shown in Table 2.

The simulation results for the neutral current in the case of the balanced RC load are shown in Fig. 12. The neutral current is attenuated from $25 \mathrm{~A}$ to less than $3 \mathrm{~A}$ (RMS). The harmonic content of the neutral current is reported in Fig. 13. In this case the THD of the voltage in the PCC is less than $2.5 \%$.

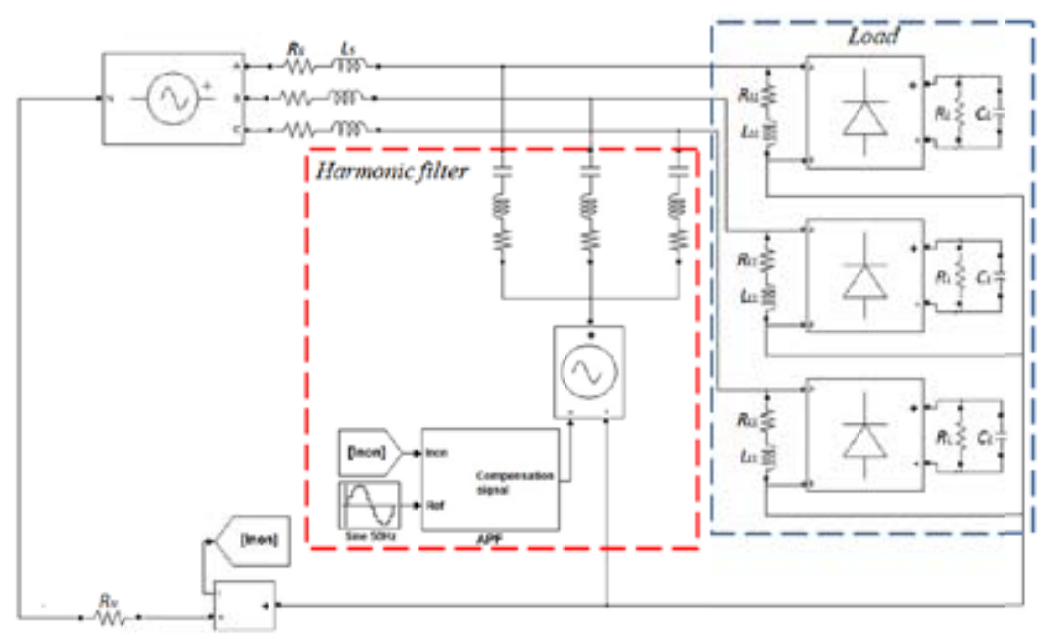

Fig. 11. The MATLAB model of the hybrid filter and the distribution power system (RC load)

Table 2. Model parameters used in the simulation ( $\mathrm{RC}$ load)

\begin{tabular}{|c|c|}
\hline Parameter & Value \\
\hline $\mathrm{R}_{\mathrm{S}}, \mathrm{L}_{\mathrm{S}}$ & $0,1 \mathrm{~W}, 318 \mu \mathrm{H}$ \\
\hline $\mathrm{R}_{\mathrm{N}}$ & $0,1 \Omega$ \\
\hline $\mathrm{R}_{\mathrm{L}}, \mathrm{L}_{\mathrm{L}}, \mathrm{C}_{\mathrm{L}}$ & $40 \Omega, 937.5 \mu \mathrm{F}$ \\
\hline $\mathrm{R}_{\mathrm{LL}}, \mathrm{L}_{\mathrm{LL}}$ & $15 \Omega, 47.7 \mathrm{mH}$ \\
\hline $\mathrm{V}_{\mathrm{S}}$ & $220 \mathrm{~V}, 50 \mathrm{~Hz}$ \\
\hline
\end{tabular}

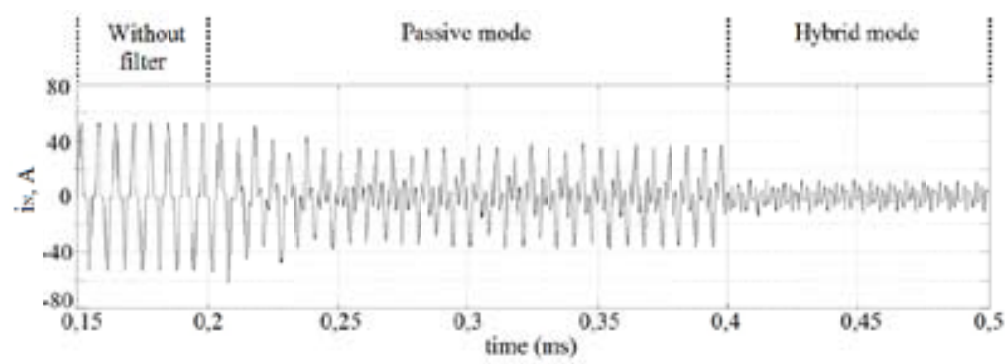

Fig. 12. Waveform of the neutral line current $I_{N}$ (balanced RC load) 
The simulation results for the neutral current for the unbalanced RC load are shown in Fig. 14. The harmonic content of the neutral current is reported in Fig. 15.

Simulation results verify that the proposed hybrid filter is able to compensate for harmonic neutral currents in cases when nonlinear load has characteristics of current source or voltage source.

\section{Conclusion}

The overload of the neutral conductor is becoming a serious problem in modern three-phase four wire distribution low voltage power systems. In this paper, a hybrid filter is proposed to compensate

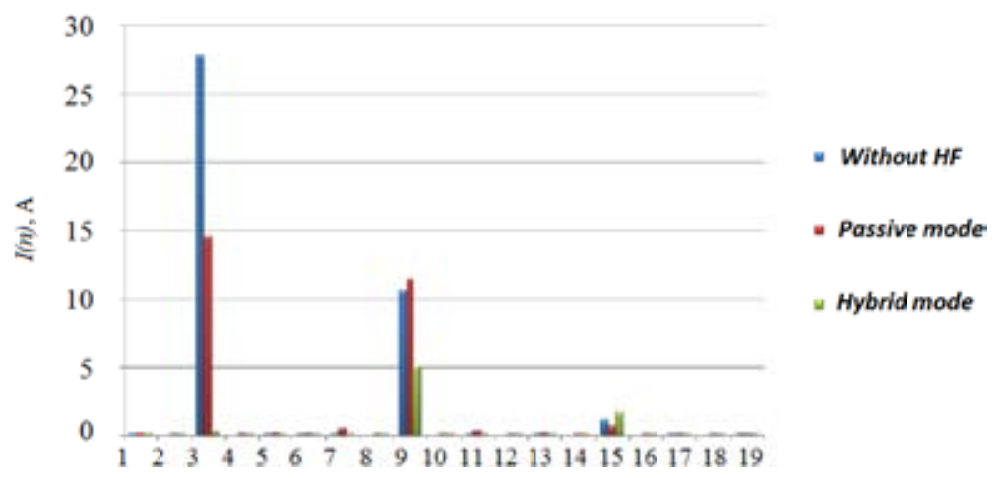

Fig. 13. Spectrum of the neutral line current $I_{N}$ (balanced RC load)

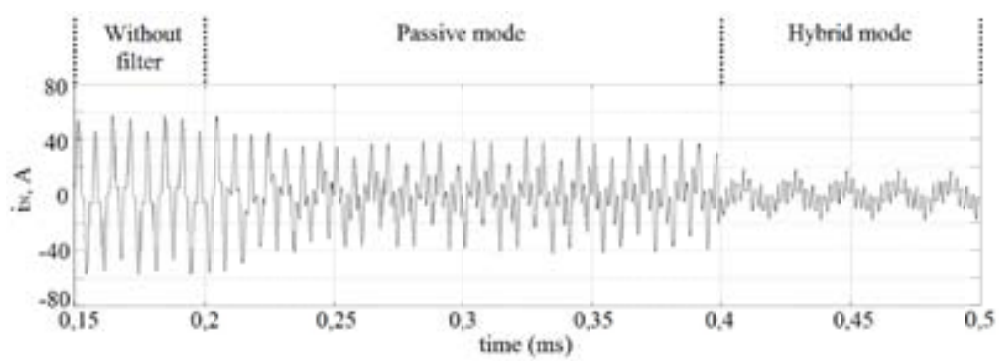

Fig. 14. Waveform of the neutral line current $I_{N}$ (unbalanced RC load)

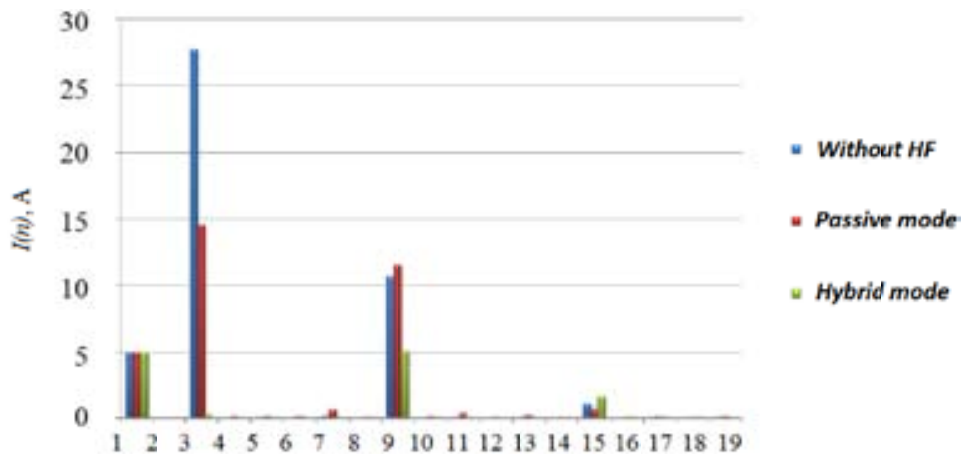

Fig. 15. Spectrum of the neutral line current $I_{N}$ (unbalanced RC load) 
harmonics and neutral current in three-phase four-wire distribution power systems. The proposed filter is composed of a three-phase passive filter and a single-phase power converter connected in series. The output voltage of the active filter is proportional to harmonic components of the neutral-line current.

The simulation results verify that the proposed filter demonstrates good compensation characteristics for different nonlinear loads. It can provide a better neutral current mitigation than the passive filter.

\section{References}

[1] Key T., Lai J.-S. Analysis of harmonic mitigation methods for building wiring systems, IEEE transactions on power systems, 1998, 13(3), 890-897.

[2] Pomilio J., Deckmann S. Characterization and compensation of harmonics and reactive power of residential and commercial loads, IEEE transactions on power delivery, 2007, 22(2), 10491055.

[3] Gruzs T.M. A survey of neutral currents in three-phase computer power systems, IEEE Trans. on Industry Application, 1990, 26(4), 719-725.

[4] Jou H.L., Wu J.C., Wu K.D., Chiang W.J., Chen Y.H. Analysis of zig-zag transformer applying in the three-phase four-wire distribution power system, IEEE transactions on power delivery, 2005, 20(2), 1168-1178.

[5] Choi S., Jang M. A reduced-rating hybrid filter to suppress neutral current harmonics in three-phase four-wire systems, IEEE transactions on industrial electronics, 2004, 51(4), 927-930.

[6] Vodyakho O., Mi C. Three-level inverter-based shunt active power filter in three-phase threewire and four-wire systems, IEEE transactions on power electronics, 2009, 24(5), 1350-1363.

[7] Aredes M., Hafner J., and Heumann K. Three-phase four-wire shunt active filter control strategies, IEEE transactions on power electronics, 1997, 12(2), 311-318.

[8] Wu J.-C., Jou H.-L., Hsiao H.-H., Xiao S.-T. A new hybrid power conditioner for suppressing harmonics and neutral-line current in three-phase four-wire distribution power systems, IEEE transactions on power delivery, 2014, 29(4), 1525-1532.

[9] Akagi H. Active harmonic filters, Proceedings of the IEEE, 2005, 93(12), 2128-2141.

[10] Cirrincione M., Pucci M., Vitale G., Miraoui A. Current harmonic compensation by a single-phase shunt active power filter controlled by adaptive neural filtering, IEEE trans. on Industrial Electronics, 2009, 56(8), 3128-3143.

[11] Temerbaev S., Dovgun V. Improvement of Power Quality in Distributed Generation Systems Using Hybrid Power Filters, in Proc. Harmonics and Quality of Power, ICHQP, 2014, 694-698.

[12] Peng F. Harmonic sources and filtering approaches, IEEE industry application magazine, 2011, 7(4), 18-25. 